\title{
AN INVESTIGATION INTO WORKING BEHAVIOR CHARACTERISTICS OF PARABOLIC CFST ARCHES APPLYING STRUCTURAL STRESSING STATE THEORY
}

\author{
Jun $\mathrm{SHI}^{1}$, Kangkang YANG ${ }^{2,3}$, Kaikai ZHENG ${ }^{2,3}$, Jiyang $\mathrm{SHEN}^{2,3}$, \\ Guangchun $\mathrm{ZHOU}^{2,3 *}$, Yanxia $\mathrm{HUANG}^{4 *}$ \\ ${ }^{1}$ School of Transportation Science and Engineering, Harbin Institute of Technology, Harbin 150090, China \\ ${ }^{2}$ Key Lab of Structures Dynamic Behavior and Control of the Ministry of Education, \\ Harbin Institute of Technology, Harbin 150090, China \\ ${ }^{3}$ Key Lab of Smart Prevention and Mitigation of Civil Engineering Disasters of the Ministry of Industry and \\ Information Technology, Harbin Institute of Technology, Harbin 150090, China \\ ${ }^{4}$ Civil Engineering Faculty in Emei, Southwest Jiaotong University, Sichuan 614202, China
}

Received 10 June 2018; accepted 13 December 2018

\begin{abstract}
This paper conducts the experimental and simulative analysis of stressing state characteristics for parabolic concretefilled steel tubular (CFST) arches undergoing vertical loads. The measured stain data is firstly modeled as the generalized strain energy density (GSED) to describe structural stressing state mode. Then, the normalized GSED sum $E_{j \text { norm }}$ at each load $F_{j}$ derives the $E_{j \text {,norm }}-F_{j}$ curve reflecting the stressing state characteristics of CFST arches. Furthermore, the Mann-Kendall criterion is adopted to detect the stressing state change of the CFST arch during its load-bearing process, leading to the revelation of a vital stressing state leap characteristic according to the natural law from quantitative change to qualitative change of a system. The revealed qualitative leap characteristic updates the existing definition of the CFST arch's failure load. Finally, the accurate formula is derived to predict the failure/ultimate loads of CFST arches. Besides, a method of numerical shape function is proposed to expand the limited strain data for further analysis of the stressing state submodes. The GSED-based analysis of structural stressing state opens a new way to recognize the unseen working behavior characteristics of arch structures and the updated failure load could contribute to the improvement on the structural design codes.
\end{abstract}

Keywords: stressing state, CFST arch, energy density, leap, failure load, formula.

\section{Introduction}

The excellent load-bearing performance and architectural merit of concrete-filled steel tubular (CFST) arch bridges promote their wide engineering application in recent years (Chen, 2007; Xiao, Cai, Chen, \& Xu, 2012). Actually, the filled concrete can obviously improve the stiffness and stability of steel tubes, resulting in the rationality of structural load-bearing performance and considerable economic benefits (Han, 2000; B. C. Chen \& Y. J. Chen, 2000; Chen $\&$ Zhang, 2012). Meanwhile, the researches on the working behavior of CFST arch bridges also greatly contributed to their development around the world (Cancelliere, Imbimbo, \& Sacco, 2010; Rovero, Focacci, \& Stipo, 2013; Ma, Wang, Su, \& Mei, 2016).

However, the working behavior of CFST arches is relatively complicated because of geometric and material non- linearity, effect of initial stress and imperfection on structural stability, as well as the possible co-existence of both bending and torsional deformations (Han, Zhu, Liu, Wang, \& Xiang, 2013; Geng, Wang, Ranzi, \& Wu, 2014). Li and Zhou (2011) established one computational CFST arch bridge model to study its stability in consideration of both geometrical non-linearity and material non-linearity. The results showed that the influence of material non-linearity on the structural stability is notable. In the same year Liu, Wang, and Zhu (2011) paid attention to the ultimate loadbearing capacity of the long-span CFST arch bridge with fly-bird-type and also indicated that the effect of geometric and material nonlinearity could not be neglected. In addition, Luo, Pi, Gao, Bradford, and Hui (2015) found that the non-linear buckling analysis is better than linear buckling

*Corresponding author. E-mail: gzhou@hit.edu.cn,huangyx@home.swjtu.edu.cn 
analysis in assessing the long-term serviceability limit state of CFST shallow arches in design practice. However, these research results were still limited in the traditional understanding on structural behavior. As a result, although some formulas have been proposed to calculate the load-bearing capacity of CFST arch structures (Wu, Liu, W. Wang, \& Y. Y. Wang, 2015; Liu, Wang, Wu, \& Zhang, 2017), they are considerably inaccurate when compared with experimental results (Pi \& Trahair, 1999).

Specifically speaking, the present researches encounter the bottleneck problems. The conventional methods for analyzing CFST arches mainly focus on the ultimate load-bearing state with considerable random property, so the formulas derived from the theoretical and experimental analysis cannot accurately calculate the failure loads of CFST arches. Besides, as composite structures, CFST arches need many experiments to investigate their internal working behavior and failure mechanism. But the experimental cost of CFST arches is so high that the existing experimental data is insufficient. Moreover, structural analysis at present is basically guided or driven by engineering design and engineering practice. To some extent, this situation limits the efforts to discover the unseen structural behavior characteristics since the engineering guidance requires common conservative recognition.

The problems mentioned above indicate that some unseen behavior characteristics of CFST arches have not been revealed from both experimental and simulative data. Logically, this also implies that the new theories and methods should be developed to model structural working state so as to disclose the unseen structural working characteristics. Therefore, this paper investigates the working behavior of parabolic CFST arches from a new perspective of structural stressing state theory. The measured strain data of the CFST arch is modeled as generalized strain energy density (GSED) to express the stressing state mode which is characterized by the corresponding GSED sum. According to the natural law from quantitative change to qualitative change of a system, the CFST arch's stressing mode will certainly embody a qualitative leap from the quantitative change with load increase. Thus, the MannKendall (M-K) criterion (Mann, 1945; Kendall, 1957; Hirsch, Slack, \& Smith, 1982) is adopted to distinguish the leap characteristic of the CFST arch's stressing mode, leading to the update of the present definition of the CFST arch's failure load. Then, using the method of numerical shape function, the limited experimental data is expanded to further model and reflect the CFST's internal stressing state characteristics. Furthermore, the finite element (FE) analysis is conducted to verify the stressing state characteristics revealed from the experimental investigation and provides the data to fit the formula for predicting the updated failure loads of CFST arches. Finally, it is verified that the fitted formula can accurately predict the updated failure loads of the arches and be analogously applied to calculate the ultimate loads, providing a reference to the improvement on the existing design code.

\section{The theory for analysing structural stressing state}

\subsection{Modeling of structural stressing state}

The stressing state of a loaded structure is defined as the structural working behavior, characterized by the distribution patterns of responses which are formed by the structural key points' strains, GESDs, displacements, etc. That is to say, an instant structural stressing state can be completely expressed by the numerical mode consisting of the mechanical responses of all concerned points. This numerical mode is called as structural stressing state mode. In this study, GSED is applied to express the stressing state at the measured point (Huang, Y. Zhang, M. Zhang, \& Zhou, 2014; Shi, Li, Chen, Zheng, \& Zhou, 2018), that is

$$
E_{i j}=\int_{0}^{\varepsilon_{i j}} \sigma \mathrm{d} \varepsilon
$$

where $E_{i j}$ is the GSED value of the $i$-th measured point under the $j$-th load; $\varepsilon_{i j}$ is the strain value of the $i$-th point under the $j$-th load. Thus, the numerical mode of structural stressing state can be expressed by a vector or a matrix. Accordingly, the normalized GSED sum $E_{j \text {,norm }}$ under the $j$-th load is then proposed to characterize structural stressing state mode, that is

$$
E_{j, \text { norm }}=\frac{\sum_{i=1}^{N} E_{i j}}{E_{\mathrm{M}}}
$$

in which $N$ is the total number of the measured points; $E_{\mathrm{M}}$ is the maximum GSED sum over the whole loading process. Thus, the $E_{j, \text { norm }}-F_{j}$ curve of the CFST arch can be plotted to investigate structural stressing state characteristics.

\subsection{Detection of structural stressing state characteristics}

The $\mathrm{M}-\mathrm{K}$ criterion is applied to detect the mutation of structural stressing state from the $E_{j \text {,norm }}-F_{j}$ curve, for it is a widely used trend analysis tool currently without necessity for samples to comply with a certain distribution or to adapt to some interference of a few outliners. Here, it is assumed that the sequence of $E_{j, \text { norm }}$ (the load step $j=1,2, \ldots, n)$ is statistically independent. Actually, the relevant and independent ingredients coexist in the structural stressing state at different load steps to a certain extent. According to the Saint Venant's principle, structural components which are located far away from each other have little spatial relevance or mutual effects, leading to considerable ingredients of independence in the experimental data (strains, displacements, etc.) at different locations. Besides, the inherent randomness in the experimental model and material properties result in a significant independent content at different load steps as well. Also, from the effectiveness of the M-K criterion, which will be discussed later, this analytical method could be valid in view of the "result-oriented" consideration. Hence, the 


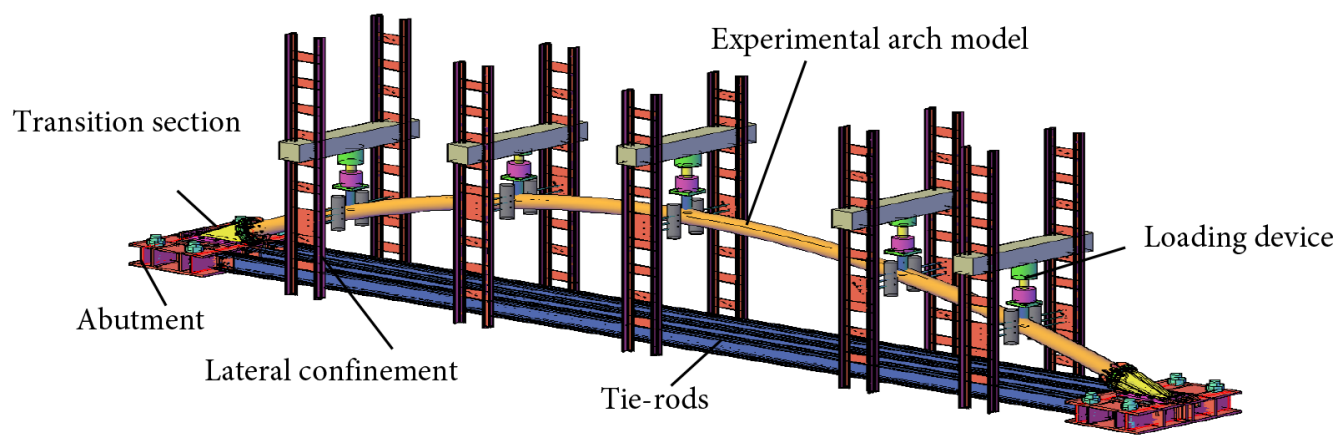

Figure 1. The experimental model and apparatus of the arch

leap characteristic of the structural working behavior can be detected approximately through the M-K criterion. The procedure of the $\mathrm{M}-\mathrm{K}$ criterion is as follows:

1. For an $E-F$ curve, take cumulative number $m_{i}$ that $E_{i}$ is greater than $E_{j}(1 \leq j \leq i)$ from the sequence $\left(E_{1}\right.$, $\left.E_{2}, \ldots, E_{n}\right)$

2. Define statistical quantity $q_{k}$ with mean $E\left(q_{k}\right)$ and variance $v\left(q_{k}\right)$;

$$
\begin{aligned}
& q_{k}=\sum_{i=1}^{k} m_{i}(2 \leq k \leq n) ; \\
& E\left(q_{k}\right)=k(k-1) / 4 ; \\
& v\left(q_{k}\right)=k(k-1)(2 k+5) / 72 ;
\end{aligned}
$$

3. Normalize $q_{k}$ to obtain its gradient $U F_{k}$, i.e., obtain the $U F_{k}-F_{j}$ curve:

$$
U F_{k}=\left(q_{k}-E\left(q_{k}\right)\right) / \sqrt{v\left(q_{k}\right)}
$$

4. Repeat steps (a) and (b) for the sequence inverse $\left(E_{n}\right.$, $\left.\ldots, E_{2}, E_{1}\right)$;

5. Normalize the new $q_{k}$ to obtain its gradient $U B_{k}$ ' and then form the $U B_{k}-F_{j}$ curve;

$$
\begin{aligned}
& U B_{k}^{\prime}=-\left(q_{k}-E\left(q_{k}\right)\right) / \sqrt{v\left(q_{k}\right)} ; \\
& U B_{k}=U B_{n-k+1}^{\prime} ;
\end{aligned}
$$

6. The intersecting point of the $U F_{k}$ and $U B_{k}$ curves is the leap point of the $E-F$ curve.

\section{Experiment of CFST arches}

\subsection{Experimental CFST arches}

Liu et al. (2017) conducted the experiment of the parabolic CFST arches with three different sizes and subjected to three different loading cases: a vertical load at the mid-span (loading case 1), a vertical load at a one-quarter point (loading case 2) and uniformly vertical loads (loading case 3). All these arches have $9 \mathrm{~m}$ in span, 0.12 in steel ratio, $159 \mathrm{~mm}$ in diameter and $4.5 \mathrm{~mm}$ in thickness of steel tube. The yield stress, elastic modulus of steel and cubic compressive strength of concrete are 376.2 MPa, $204 \mathrm{GPa}$ and $41.60 \mathrm{MPa}$, respectively. Table 1 shows the configurational parameters of the arches, in which $f, L, f / L$ and $\lambda$ are raise height, span, rise-span ratio and slenderness ratio, respectively.

Figure 1 shows the experimental model and the apparatus with six parts. The arch model and abutment are connected by the transition section. Abutments are fixed on the ground using anchor blocks. Tie-rods between abutments are used to balance the horizontal thrust from arch feet. The out-of-plane deformation of the arch is limited by lateral confinements. To simulate the process of loading case 3, five loading devices are set at equal intervals along the arch span where the jacks exert controllable loading process.

\subsection{Loading scheme}

To check the functions of the devices, the arch was preloaded before the formal loading process. In the preloading stage, the load was applied step by step $(5 \mathrm{kN}$ each level) until $0.3 \mathrm{Pu}(\mathrm{Pu}$ is the ultimate load of the arch obtained from FE analysis). In the formal loading stage, the load was applied step by step until $0.7 P u$, i.e. $10 \mathrm{kN}$ each load level before $0.5 P u$ and then $5 \mathrm{kN}$. After $0.7 P u$, the load was continuously applied until the failure of the arch.

\subsection{Measuring scheme}

As shown in Figure 2(a), under loading cases 1 or 2, the displacement meters are placed at spans $L / 8, L / 4,3 L / 8$, $L / 2,5 L / 8,3 L / 4$ and $7 L / 8$ to monitor the vertical displacements of the arch. The displacement meters installed at the arch bases are to monitor the horizontal displacements

Table 1. The configurational parameters of the experimental arches

\begin{tabular}{|c|c|c|c|c|}
\hline Loading case & Arch No. & $f(\mathrm{~m})$ & $f / L$ & $\lambda$ \\
\hline \multirow{3}{*}{1} & $\mathrm{~A}$ & 2.0 & $1 / 4.5$ & 91 \\
& $\mathrm{~B}$ & 1.5 & $1 / 6$ & 87 \\
& $\mathrm{C}$ & 1.0 & $1 / 9$ & 84 \\
\hline \multirow{3}{*}{2} & $\mathrm{D}$ & 2.0 & $1 / 4.5$ & 91 \\
& $\mathrm{E}$ & 1.5 & $1 / 6$ & 87 \\
& $\mathrm{~F}$ & 1.0 & $1 / 9$ & 84 \\
\hline \multirow{3}{*}{3} & $\mathrm{G}$ & 2.0 & $1 / 4.5$ & 91 \\
& $\mathrm{H}$ & 1.5 & $1 / 6$ & 87 \\
& $\mathrm{I}$ & 1.0 & $1 / 9$ & 84 \\
\hline
\end{tabular}




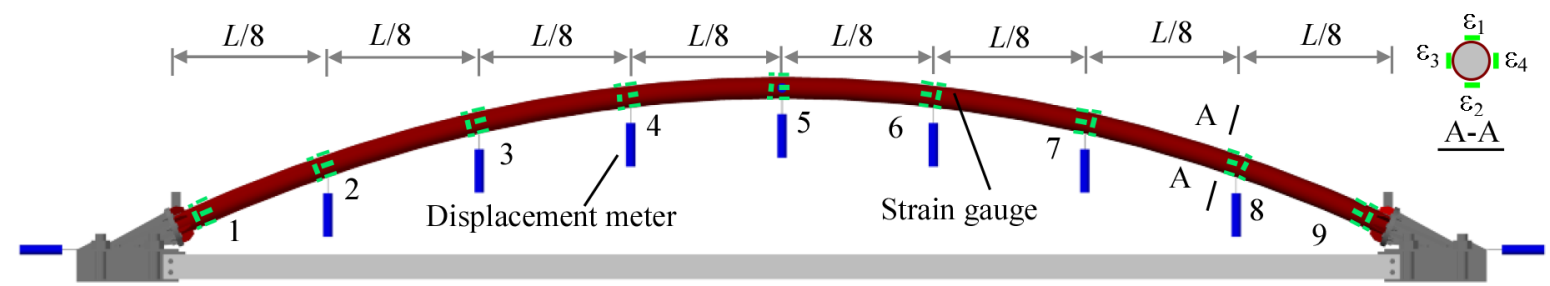

(a)

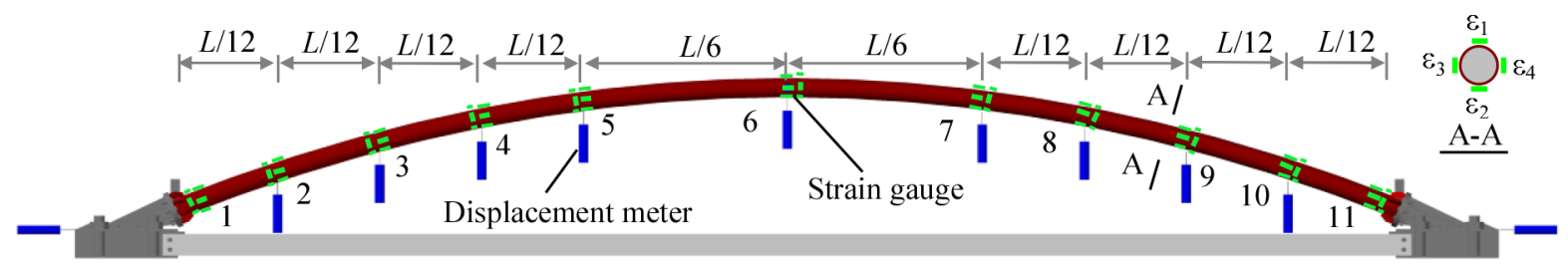

(b)

Figure 2. The measuring scheme of experimental arches under: $\mathrm{a}$ - loading case 1 or loading case 2 ; b - loading case 3

of the abutments. The strain gauges numbered $1 \sim 9$ are placed at eight equal intervals along the arch. Around each measured section, four lateral/longitudinal strain gauges are placed to monitor the corresponding strains. The antisymmetric buckling of the arch may happen under loading case 3 due to its initial imperfection. Therefore, the measured sections are set at positions $L / 12, L / 6, L / 4, L / 3$, $L / 2,2 L / 3,3 L / 4,5 L / 6$ and $11 L / 12$ as well as the arch bases in order to get consecutive deformation curves along the arch span, as shown in Figure 2(b). All these measured sections are numbered from 1 to 11 sequentially. The layout of displacement meters and strain gauges are similar to the arches under loading cases 1 or 2 .

The distribution of all measured points is mostly uniform and typical so that they can embody the working behavior characteristics of the CFST arches adequately.

\section{The GSED-based investigation into stressing states of CFST arches}

Here, the stressing state of the arch is expressed by GSED values consisting of the measured strain data, as calculated by Eqn (1). The GSED values can form a vector or matrix to describe the stressing state mode of the CFST arch. Then, Eqn (2) is used to calculate out the normalized GSED sum $\left(E_{j \text {,norm }}\right)$ under each load step $F_{j}$. Thus, the $E_{j, \text { norm }}-F_{j}$ curve can be plotted to investigate the developing tendency and sensitivity of the arch's stressing state mode.

\subsection{Investigation into $E_{j, \text { norm }}-F_{j}$ curves}

As an example, the $E_{j \text {,norm }}-F_{j}$ curve of arch $\mathrm{D}$ is plotted to characterize the structural working behavior. And two characteristic points $P(55 \mathrm{kN})$ and $Q(85 \mathrm{kN})$ in the $E_{j, \text { norm }}-F_{j}$ curve are distinguished using the M-K criterion, as shown in Figure 3. It can be seen that the characteristic parameter $E_{j, \text { norm }}$ increases slowly with loading level before $55 \mathrm{kN}$ (point $P$ ), indicating that the arch is basically in the linear-elastic working state in this stage. From $55 \mathrm{kN}$ to $85 \mathrm{kN}$ (between points $P$ and $Q$ ), arch $\mathrm{D}$ is in the elastic-plastic working state with local plastic development. When the load exceeds $85 \mathrm{kN}$ (point $Q$ ), the $E_{j, \text { norm }}-F_{j}$ curve increases sharply and arch D enters the unstable stressing state until its global failure at ultimate load $(107 \mathrm{kN})$.

It could be comprehended that characteristic point $P$ is the transition point where the arch's stressing state changes from elasticity to elastoplasticity. Although some parts in the arch take a form of plasticity, the whole arch structure keeps a stable working state until point $Q$. Then the stressing state of arch D qualitatively changes or leaps to a new state different from the previous one, i.e., arch D loses its normal and stable stressing state and starts its developing failure state. Therefore, the load corresponding to characteristic point $Q$ is defined as the failure load of the arch, and the present failure load is just called as the ultimate load. It needs to further state that this updated failure load is derived from the revelation of the structural stressing state characteristic instead of any assumption and accords with the natural law from quantitative change to qualitative change of a system.

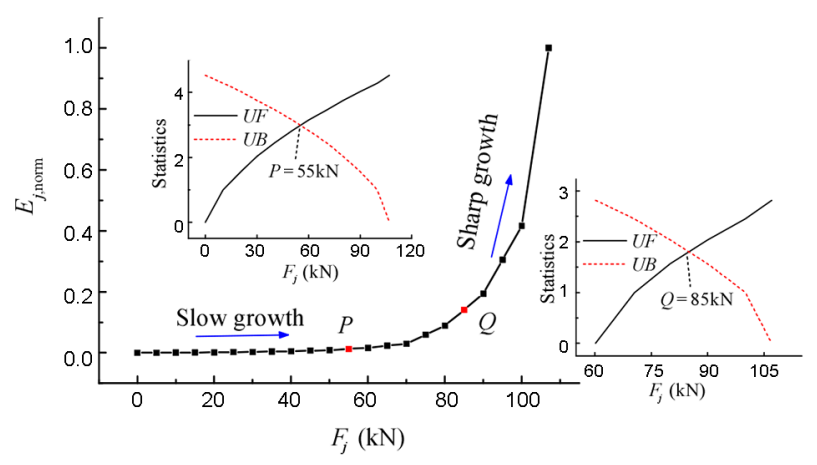

Figure 3. The $E_{j, \text { norm }}-F_{j}$ curve of arch D and the characteristic points $P$ and $Q$ 


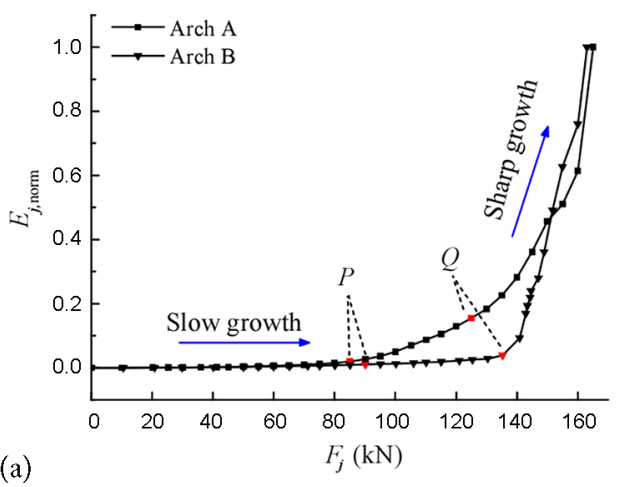

(a)
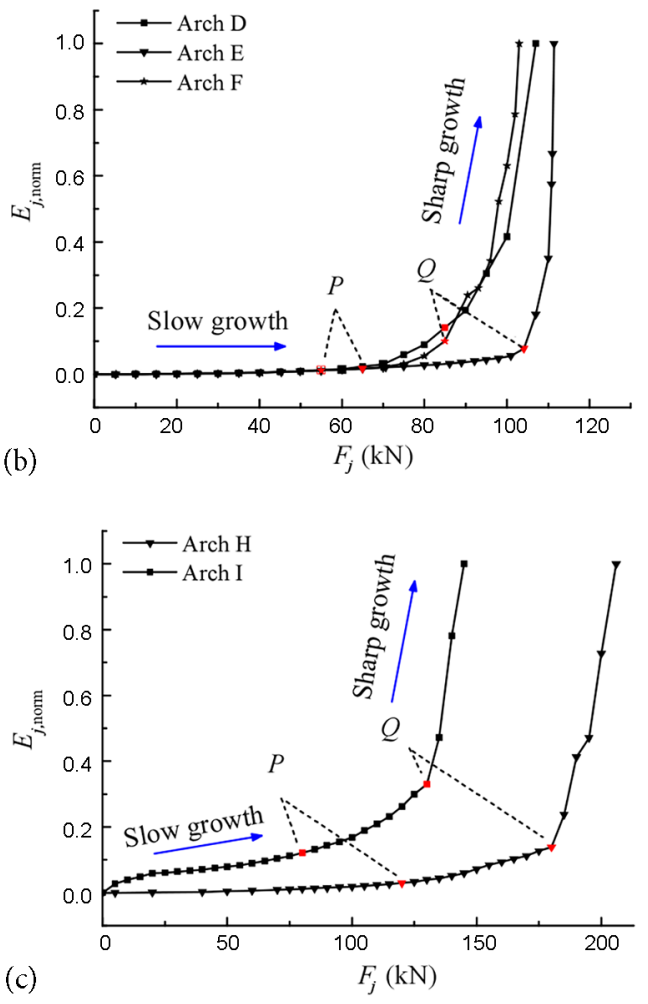

Figure 4. The $E_{j, \text { norm }}-F_{j}$ curves of experimental arches under different loading cases: a - loading case $1 ; \mathrm{b}$ - loading case 2; c - loading case 3

Also, the failure loads of other experimental arches can be found from their $E_{j, \text { norm }}-F_{j}$ curves by using the $\mathrm{M}-\mathrm{K}$ criterion, as shown in Figure 4 . Evidently, the general characteristic points (points $P$ and $Q$ ), exist in all the arches. Hence, the transition point and the failure load are the reflection and description of general structural stressing state characteristic; in other words, the characteristic points $P$ and $Q$ are the embodiment of the natural law instead of an empirical judgment or a statistical estimation.

\subsection{Characteristics of structural strains and displacements}

As stated above, the stressing states of CFST arches will leap around the failure load (from a stable stressing state to a failure state). The strains measured at representative locations on a CFST arch can certainly include its internal working behavior characteristics, but the strain data need to be modeled to reflect the characteristics. Here, the GSED values of one cross section, $\boldsymbol{E}=\left[E_{1}, E_{2}, \ldots, E_{j}\right.$, ...], are adopted to describe the arch's stressing state mode which is characterized by GSED sum, that is

$$
E_{j}=\sum_{i=1}^{4} \int_{0}^{\varepsilon_{i}} \sigma \mathrm{d} \varepsilon,
$$

where $E_{j}$ is the sum of GSED values to the four strains on a section under the $j$-th load; $\sigma$ is the stress corresponding to $\varepsilon$ by referring to the constituent curve $\sigma-\varepsilon$. Thus, the stressing state mode can be written as a vector $\mathbf{S}=\left[\boldsymbol{E}_{1}, \boldsymbol{E}_{2}\right.$, $\left.\ldots, \boldsymbol{E}_{\mathrm{n}}\right]^{\mathrm{T}}$. Then, the change of the GSED distribution mode can be plotted to observe the change of the CFST arch's stressing state mode.

Also, arch D is exampled to demonstrate the structural stressing state leap embodied by its stressing state mode, the vector $\mathbf{S}=\left[\boldsymbol{E}_{1}, \boldsymbol{E}_{2}, \ldots, \boldsymbol{E}_{9}\right]^{\mathrm{T}}$ with the load increase (the $S$-load curve), as the other experimental arches have similar stressing state characteristics. As shown in Figure 5(a), the dash lines correspond to the transition load and failure load of the arch. It can be seen that $\mathbf{S}$ keeps a slight and stable increase before $55 \mathrm{kN}$. From then on, the $\mathbf{S}$ increases greatly faster than others at the arch foot, indicating that the zone around the arch foot (section 9) is the weak part of the arch where plays a decisive role in the instability failure of the arch. Importantly, Figure 5(a) evidently embodies the mutation of the arch's stressing state mode around $85 \mathrm{kN}$; actually, the arch goes into another different stressing state after the failure load $(85 \mathrm{kN})$. Correspondingly, the characteristic parameter of the stressing state mode $\mathbf{S}$, the increment $\Delta E_{j}$ of $\mathbf{S}$ between adjacent loads for the key section, is proposed to intuitively observe the stressing state characteristics with load increase, as shown
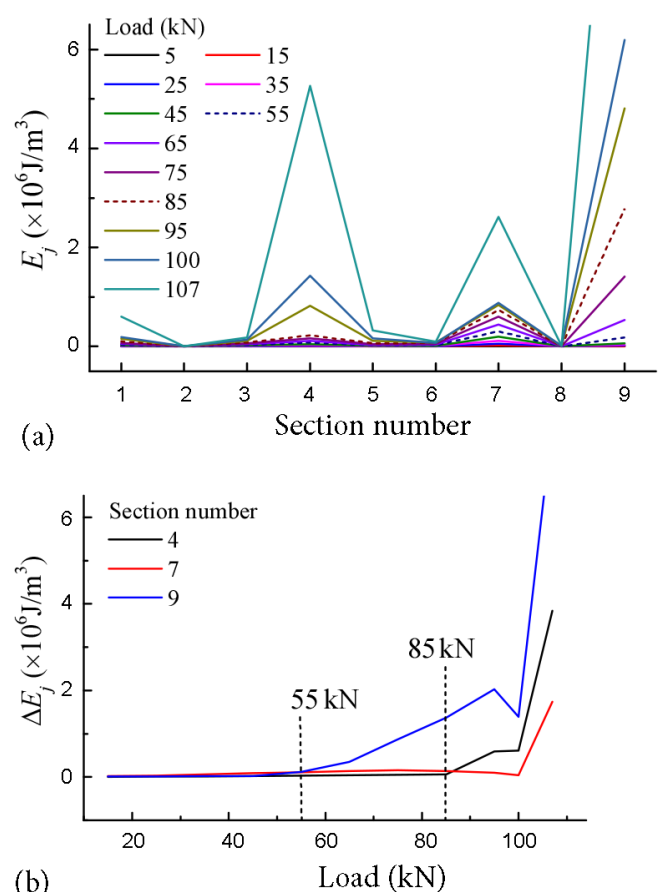

Figure 5. The GSED-based stressing state mode of arch D: a - the $\mathbf{S}$-load curve; b - the $\Delta E_{j}$-load curves 
in Figure 5(b). The bifurcation characteristic of stressing state mode is disclosed at the characteristic loads $55 \mathrm{kN}$ or $85 \mathrm{kN}$, which indicates the stressing state leap of arch D.

In addition, all the measured displacements at the representative points of the arch can also form the structural stressing state mode as a vector or a matrix. The displacement distribution mode is generally the external appearance of structural stressing state. For arch D, we can form the stressing state mode using the measured displacements (the vector $\boldsymbol{S}_{\boldsymbol{d}}=\left[\boldsymbol{d}_{1}, \boldsymbol{d}_{3}, \boldsymbol{d}_{5}, \boldsymbol{d}_{7}, \mathbf{d}_{9}\right]^{\mathrm{T}}$ and its characteristic parameter using the displacement increment between adjacent loads (the parameter $\Delta d$ ). Thus, the $\boldsymbol{S}_{\boldsymbol{d}}$-load and $\Delta d$-load curves can be plotted to observe the leap characteristic of arch D's stressing state, as shown in Figure 6. It can be seen that the dash lines correspond to two characteristic points, $55 \mathrm{kN}$ and $85 \mathrm{kN}$. The displacement develops steadily in small amplitude before the ultimate load. The antisymmetric shape of the curve corresponds to the asymmetrical single-point loading mode. The mutation characteristic at the failure load $85 \mathrm{kN}$ is not explicitly shown in the distribution modes of displacements, implying that the macroscopic physical quantity like displacement could not obviously reflect the qualitative change/ mutation of the arch's internal stressing state at failure load sometimes, because the limited measuring points of displacements may miss some critical stressing state information.

The CFST arches mainly undergo sectional axial compression and bending moment. Hence, both axial and bending stressing state modes of the arch can be made to reflect its stressing state characteristics. Here the normal strain of sectional centroid point is taken as the quantitative index to representatively express the axial stressing

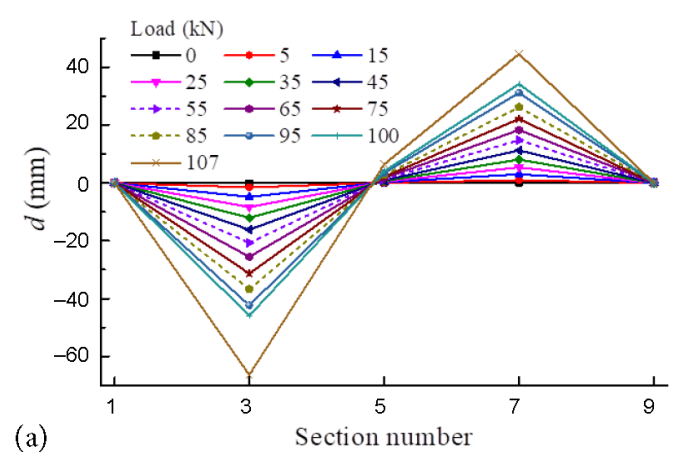

(a)

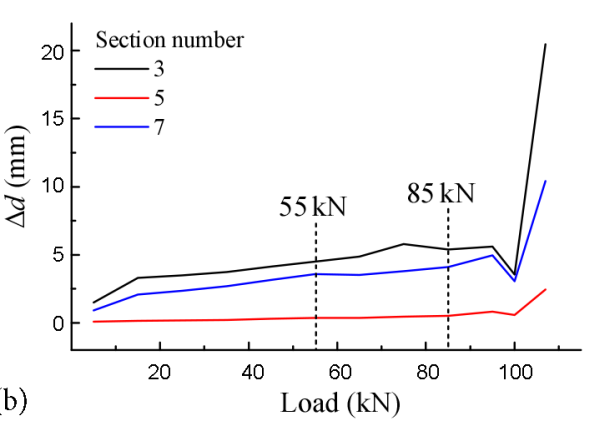

Figure 6. The displacement-based stressing state mode of arch D: a - the $\mathbf{S}_{d}$-load curve; b - the $\Delta d$-load curve state mode. However, the single normal strain on a cross section could not fully evaluate the axial stressing state mode, as the measured strain has high variability, weak robustness and poor stability. Therefore, the average sectional strain called as "axial strain" is taken to investigate the change of the axial stressing state mode, as calculated by Eqn (10):

$$
\bar{\varepsilon}_{N}^{\text {axial }}=\frac{\varepsilon_{1 N}+\varepsilon_{2 N}+\varepsilon_{3 N}+\varepsilon_{4 N}}{4},
$$

where $\bar{\varepsilon}_{N}^{\text {axial }}$ is the average value of sectional longitudinal strains $\left(\varepsilon_{1 N}, \varepsilon_{2 N}, \varepsilon_{3 N}, \varepsilon_{4 N}\right)$ on the $N$-th section. Thus, the vector $\boldsymbol{S}_{\text {axial }}=\left[\bar{\varepsilon}_{1}^{\text {axial }}, \bar{\varepsilon}_{2}^{\text {axial }}, \ldots, \bar{\varepsilon}_{9}^{\text {axial }}\right]^{\mathrm{T}}$ (9 measured sections) is the axial stressing state mode or the stressing state mode for axial forces. Correspondingly, the characteristic parameter, the increment $\Delta \bar{\varepsilon}_{N}^{\text {axial }}$ of the average sectional strains between adjacent loads is proposed as the characteristic parameter of $\mathbf{S}_{\text {axial }}$.

Similarly, the bending stressing state mode of arch D can be made by the generalized bending strain $\bar{\varepsilon}_{N}^{\text {bend }}$ :

$$
\bar{\varepsilon}_{N}^{\text {bend }}=\frac{\varepsilon_{1 N}-\varepsilon_{2 N}}{2}
$$

where $\varepsilon_{1 N}$ and $\varepsilon_{2 N}$ are the sectional strains of the $N$-th section. Thus, the vector $\mathbf{S}_{\text {bend }}=\left[\bar{\varepsilon}_{1}^{\text {bend }}, \bar{\varepsilon}_{2}^{\text {bend }}, \ldots, \bar{\varepsilon}_{9}^{\text {bend }}\right]^{\mathrm{T}}$ (9 measured sections) is the bending stressing state mode or the stressing state mode for bending moments. Correspondingly, the characteristic parameter, the increment $\Delta \bar{\varepsilon}_{N}^{\text {bend }}$ of the generalized bending strains between adjacent loads is proposed as the characteristic parameter of $\mathbf{S}_{\text {bend }}$.

Figure 7 shows the changing features of arch D's axial and bending stressing state submodes $\mathbf{S}_{\text {axial }}$ and $\mathbf{S}_{\text {bend }}$ as well as the corresponding characteristic parameters $\Delta \bar{\varepsilon}_{N}^{\text {axial }}$ and $\Delta \bar{\varepsilon}_{N}^{\text {bend }}$ with loading increase. It can be seen from Figures 7 (a) and (c) that due to the sensitivity of the arch foot, the curves show great values at section 9. Before $85 \mathrm{kN}$, the developing trends of both $\mathbf{S}_{\text {axial }}$ and $\mathbf{S}_{\text {bend }}$ are stable with light undulation (especially section 4 ) and then change with great increments which reflect the leap characteristic of the stressing state modes at the failure load. From Figures 7 (b) and (d), it can be seen that the key sections 4 and 7 play the main role in the qualitative leap of different structural stressing states at the updated failure load.

Furthermore, as the axial and bending stressing state modes $\mathbf{S}_{\text {axial }}$ and $\mathbf{S}_{\text {bend }}$ are essentially and mechanically different, we propose their energy-based characteristic parameters. Specifically speaking, the energy densities per unit micro-segment corresponding to the axial and bending deformation forms, respectively, are calculated based on the elastic theory in a generalized and analogous sense:

$$
\begin{aligned}
& E_{\text {axial }}=\sum_{i=1}^{N} \frac{1}{2} N \bar{\varepsilon}_{i}^{\text {axial }}=\sum_{i=1}^{N} \frac{1}{2} E A\left(\bar{\varepsilon}_{i}^{\text {axial }}\right)^{2} ; \\
& E_{\text {bend }}=\sum_{i=1}^{N} \frac{1}{2} M \kappa_{i}=\sum_{i=1}^{N} \frac{1}{2} E I \kappa_{i}^{2}, \kappa_{i}=\frac{2 \bar{\varepsilon}_{i}^{\text {bend }}}{h},
\end{aligned}
$$




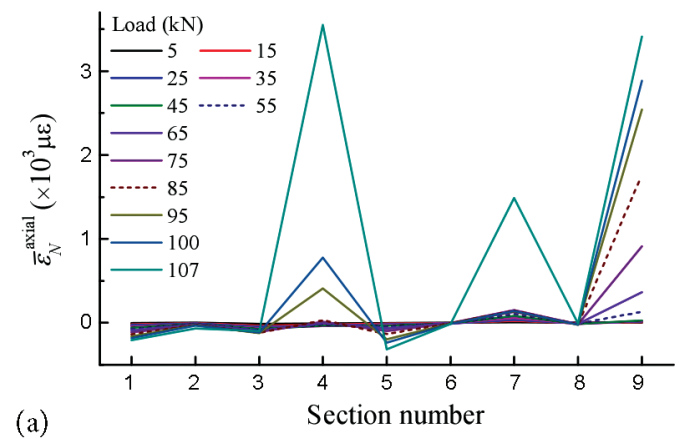

(a)
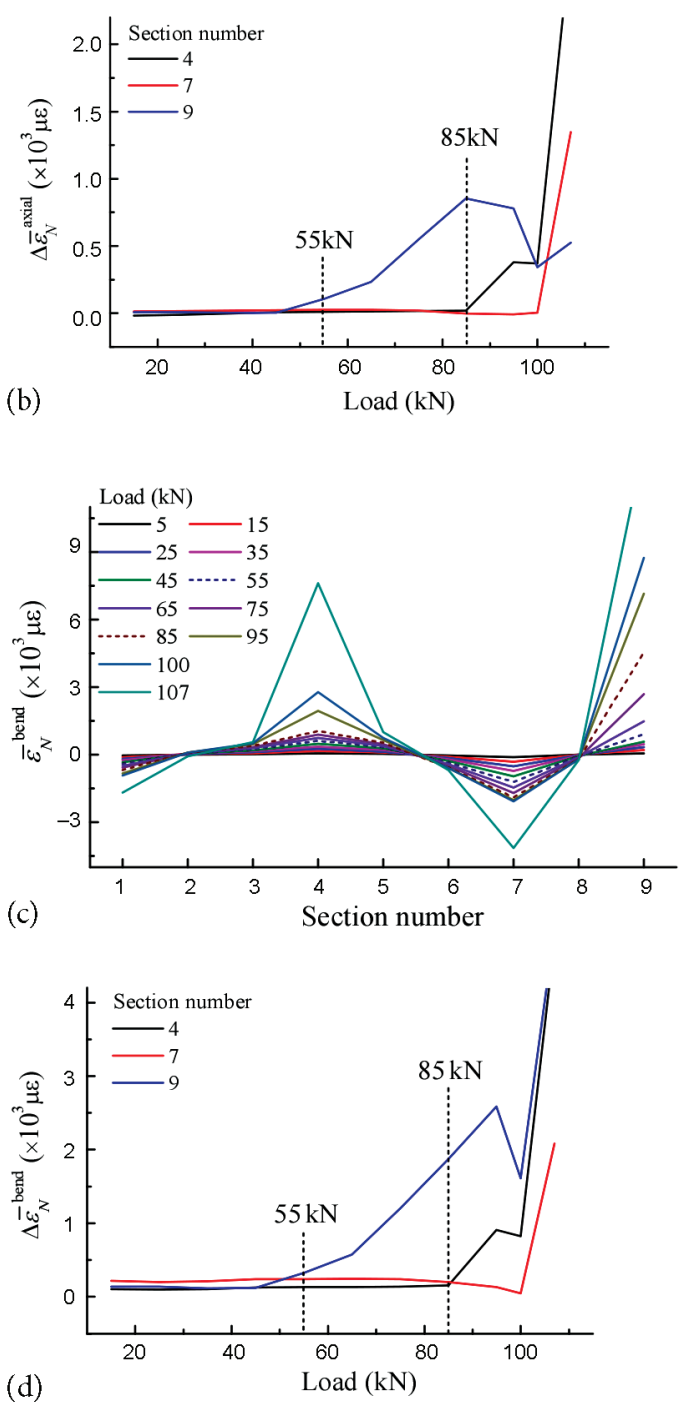

Figure 7. The stressing state sunmodes of arch D: a - the $\mathbf{S}_{\text {axial }}{ }^{-}$ load curve; b - the $\Delta \bar{\varepsilon}_{N}^{\text {axial }}$-load curve; c - the $\mathbf{S}_{\text {bend }}$-load curve; $\mathrm{d}-$ the $\Delta \bar{\varepsilon}_{N}^{\text {bend }}$-load curve

where $E_{\text {axial }}$ and $E_{\text {bend }}$ are the arch's generalized energy densities of the structural axial and bending responses, respectively; $A$ and $I$ denote sectional area and moment of inertia, respectively; $k$ is curvature for cross section; $N=9$ is the total number of cross sections here. From the $E_{\text {axial }}{ }^{-}$

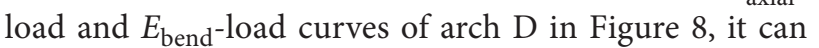
be observed that $E_{\text {axial }}$ and $E_{\text {bend }}$ are nearly equal before $55 \mathrm{kN}$ and then begin to produce disparity. After $85 \mathrm{kN}$, $E_{\text {bend }}$ significantly increases higher than $E_{\text {axial }}$, demon-

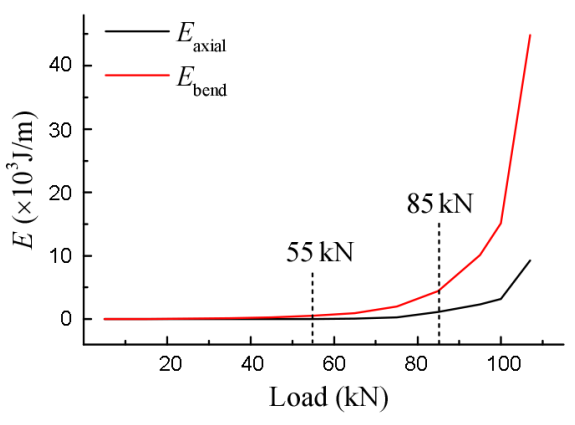

Figure 8. The $E_{\text {axial }}$-load and $E_{\text {bend }}$-load curves of arch D

strating the bending effect plays a control role during the load-bearing process of arch $\mathrm{D}$.

In total, a CFST arch will enter the unstable stressing state from the failure load on, qualitatively different from the stable one before the failure load. In fact, this characteristic is the common and essential working behavior of structural stressing state, in other words, this is an inherent attribute and the law of structural working process. Therefore, the existing failure load of the CFST arch should be updated at this stressing state leap point $Q$. What's more, the axial and bending stressing state modes can be compared in terms of energy and find out the main factor governing structural stressing state.

\section{Expansion of experimental data and application in stressing state analysis}

As illustrated above, the CFST arch's stressing state will qualitatively leap around the failure load. This essential characteristic promotes a further analysis of the stressing state submodes for the individual components and some internal forces in the CFST arch. However, a key component (cross section) just has several measured points which could not reflect the stressing state characteristics fully. Hence, the numerical shape function (NSF) method is used to obtain internal forces or deformations of the whole cross sections, so that structural stressing state can be accurately analyzed based on limited measured data.

\subsection{Method of numerical shape function}

The shape function is a smooth continuous function defined inside the element and needs to satisfy the general conditions (Wang, 2003). In the finite element method, there are a few specific shape functions constructed by low order functions, such as plane triangles, squares, tetrahedrons, etc. For example, the element displacement field function can be expressed as a linear combination of shape functions, and the node displacement is exactly the weight of the corresponding shape function. However, the application of shape functions is limited due to the following defects:

1. In terms of one element, using polynomials to construct shape functions has no explicit physical meanings and cannot accord with the real displacement field; 
2. It is difficult to construct shape functions satisfying all conditions, so a few element types exist only;

3. For irregular elements, isoparametric transformation can be used to obtain displacement interpolation fields but difficultly to obtain displacement values in global coordinates.

Therefore, it needs to develop more effective techniques for interpolating experimental data field directly through conventional shape function (Ayers, 2006; Padhi, Shenoi, Moyb, \& Mccarthya, 2001). Here, a new method of numerical shape function (NSF) is proposed to construct shape functions with explicit physical meanings. The new NSF method based on finite element simulation is introduced through the deflection field of a plate in Figure 9. The square plate model has $1 \mathrm{~m}$ in length, $0.05 \mathrm{~m}$ in thickness and $200 \mathrm{GPa}$ in elastic modulus. The plate model is simulated by element Shell 181 and meshed as $20 \times 20$ elements by ANSYS (Figure 9(a)). The deflections of four corner points and the central point have been measured as numerical shape function points. In the regular coordinate system $(\xi, \eta)$, the element displacement field $u$ can be expressed as a node displacement, that is:

$$
u=\sum_{i=1}^{4} u_{i} N_{i}(\xi, \eta),
$$

where $u_{i}$ is an element displacement at $i$-th node; $N_{i}$ is the corresponding shape function. The constructive steps are as follows:

1. Divide the plate into a certain amount of suitable elements. The relatively accurate node displacement can be calculated by establishing the overall balance equation based on the principle of virtual displacement;

2. Apply a unit displacement at node 1 along the $\mathrm{z}$-axis, while the other four nodes are fixed along the z-axis to restrict rigid displacements. The static calculation can give out the z-directional displacement $N_{1}$, as shown in Figure 9(b). Considering no large deformation or elastoplasticity, the displacement field constructed by Castigliano's theorem is independent of loading paths, and linear superposition can be carried out for the simulative results with explicit physical meanings;

3. In the same way, other numerical shape functions $N_{i}$ can be obtained, and $N_{5}$ is shown in Figure 9(c) as an example. According to the deflection of five measured points, the deflection field of the plate model can be obtained by Eqn (15):

$D=\sum u_{i} N_{i}$.

From the example, it can be seen that firstly the finite element method is used to mesh the cross section. Then, based on the measured strains, the experimental strain data on the cross section can be expanded by the shape function interpolation method to obtain each grid node's strain. Accordingly, the corresponding stress can be gained through the constitutive relation of the material. The strain energy density at each node and the normalized GSED sum $E_{j \text {,norm }}$ can be calculated by Eqn (1) and Eqn (2), respectively. Finally, the nephograms of various fields for structure responses can be obtained through the expanded data above, so that the change of structural stressing state can be further observed intuitively.

\subsection{Characteristics of structural strain fields and stress fields}

According to the NSF calculation, the strain/stress fields of one cross section can be obtained. Here the section 4 of arch D is exampled to analyze the characteristics of the strain/stress fields around failure load. Figure 10 demonstrates the contour maps of strain/stress fields on section 4 with four different load levels around the failure load $(85 \mathrm{kN})$ or at ultimate load $(107 \mathrm{kN})$. Different colors represent different strain or stress magnitudes. It can be seen from Figure 10(a) that the whole cross section is fundamentally in the compressive state with small tensile strain at $75 \mathrm{kN}$, and the shape of isopleth curves remains consistent with curves at $85 \mathrm{kN}$. The zero stress basically locates at the center of the cross section. But after $85 \mathrm{kN}$, the tensile strain occupies more than half area of the section with dramatic growth and is fairly great in value until the destruction at the ultimate load. Also the shape of isopleth curves changes from lines to curves.

As illustrated in Figure 10(b), half part of core concrete in red or yellow color (positive stress) at $75 \mathrm{kN}$ or $85 \mathrm{kN}$ indicates that the concrete is in the tension state. With the combination analysis of Figure 10(c), it can be observed that the force of both core concrete and steel tube are distributed in space symmetry before failure load ( $85 \mathrm{kN})$.

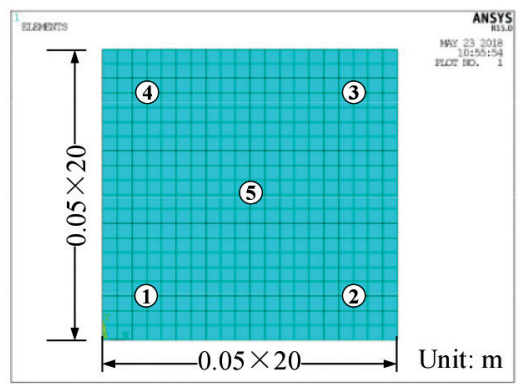

(a)

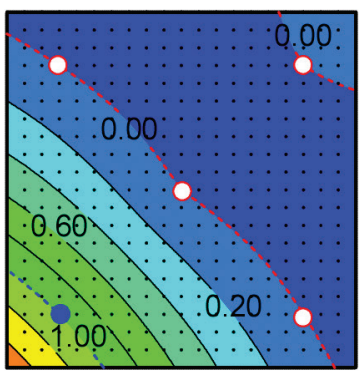

(b)

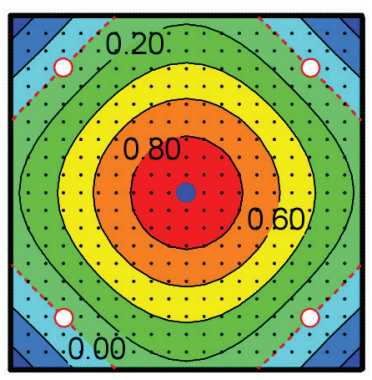

(c)

Figure 9. Finite element model and contour map of numerical shape function: a - finite element model; b - shape function $N_{1}$; c - shape function $N_{5}$ 


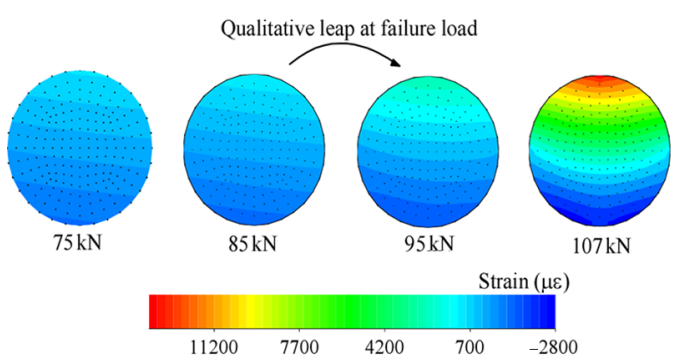

(a)

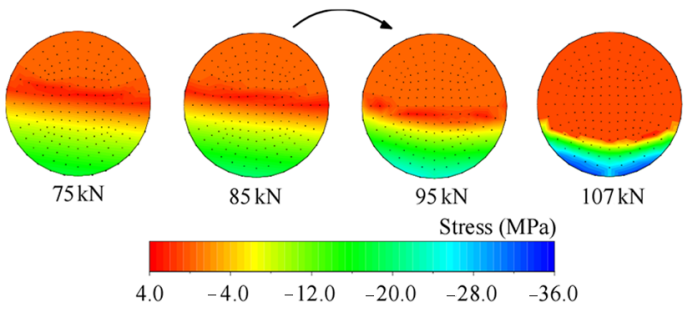

(b)

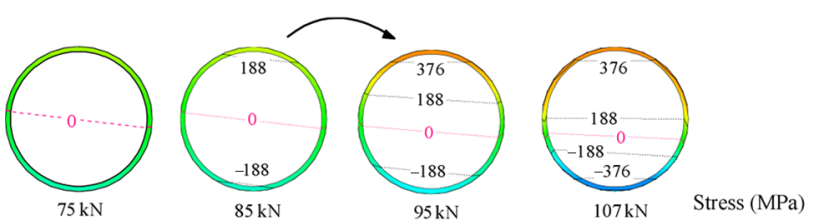

(c)

Figure 10. The contour maps of strain/stress fields on section 4: a - strain field; $b$ - stress field of concrete; c - stress filed of steel tube

After that, the tension zone of concrete is over half and most tensile stress is subjected by steel tube. With the decrease of compression zone of concrete, the bearing pulling force of steel tube is increasing. And the tensile stress of steel tube reaches the yield point.

\subsection{Characteristics of stressing state submodes for internal forces}

As introduced in Chapter 3.2, the four measured stains on one section of arch $\mathrm{D}$ is used to construct the vectors $\boldsymbol{S}_{\text {axial }}$ and $\boldsymbol{S}_{\text {bend }}$ to reflect structural axial and bending stressing state modes. Here, the stressing state submodes for internal forces can be derived from the strain/stress data of the whole cross section expanded by the NSF method. Actually, the distribution of axial force, bending moment and GSED value at each cross section can be plotted to reflect the changing characteristics of the stressing state submodes, as shown in Figure 11. There is some discrepancy between the stressing state submodes in Figure 11 when compared with those in Figure 8(a), 8(c) and Figure 6(a) derived by the measured strain data. From Figure 11(a), it can be observed that the axial forces are relatively small before $55 \mathrm{kN}$. After $55 \mathrm{kN}$, the axial forces of some cross sections have a clear increase with the load; particularly, from $85 \mathrm{kN}$ on, the axial forces on section $5 / 9$ present a considerable increase and the axial forces on section 6 changes from compression to tension, evidenc- ing the qualitative change of the axial stressing state submode around the failure load. Similar characteristics are also embodied for the bending and GSED-based stressing state submodes, as shown in Figures 11(b) and 11(c). In a sum, these characteristics evidence the qualitative change of the stressing state submodes around the failure load.

\section{Numerical investigation into stressing states of CFST arches}

The qualitative mutation of stressing states for CFST arches updates the definition of the existing failure load. Now, it is to derive the formula for calculating the updated failure loads of CFST arches. So the finite element program Abaqus (2009) is employed to perform the numerical simulation of CFST arches with different configurational and
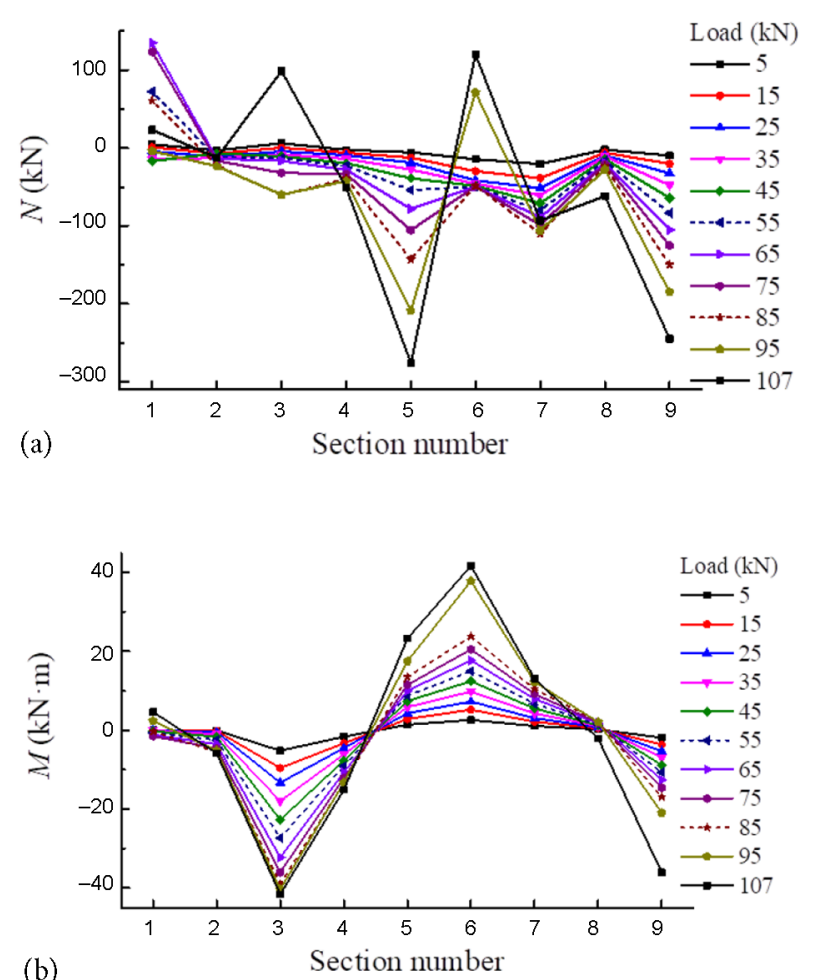

(b)

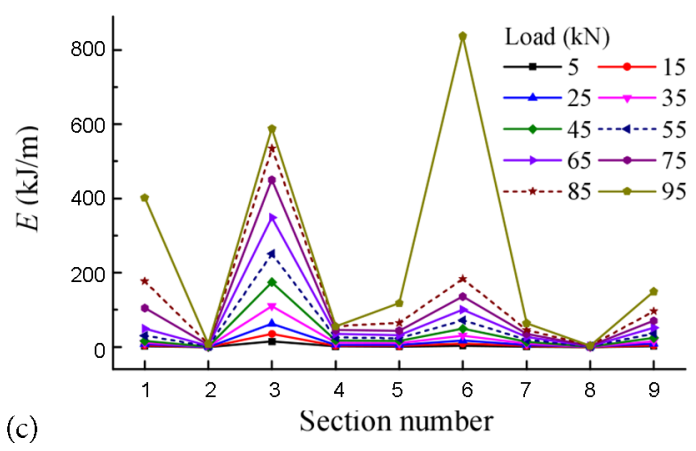

Figure 11. The stressing state submodes for internal forces of arch D: a - the distribution mode of axial force $N$; $\mathrm{b}$ - the distribution mode of bending moment $M$; $c$ - the distribution mode of GSED $E$ 
material parameters such as rise-span ratio, slenderness ratio, steel ratio and strength of steel or concrete. Then, from the output strains and displacements, the load-deflection $\left(F_{j}-d\right)$ curves and the structural GSED-load $\left(E_{j, \text { norm }}-F_{j}\right)$ curves of CFST arches can be plotted to obtain the failure loads through the detection of the M-K criterion. Thus, the formula for calculating the failure loads can be fitted using the simulative failure loads and the corresponding configurational and material parameters.

\subsection{The FE model and verification}

Figure 12 shows the FE model created by Abaqus. Beam element method (Yoshimura, Wu, Takahashi, Nakamura, \& Furukawa, 2006) for modeling CFST components is applied. To realize the coordination of two different materials at the same position, two beam elements for steel and concrete material properties separately are applied on the same location with the shared nodes. In consideration of geometric and material nonlinearity (Dessouki, Yousef, \& Fawzy, 2014), beam element B21 is used to simulate the core concrete and the steel tube of the arch with fixedends (Yin \& Lu, 2010). Also, to ensure the collective work of steel and concrete, a TIE command in Abaqus is exerted to impose tie constraints between elements. Initial geometric imperfection cannot be neglected (Han, 2007) and its shape is determined by the eigenform corresponding to the lowest buckling mode of an arch. Residual stresses do not take an account in the simulation (Pi, Liu, Bradford, \& Zhang, 2012).

Here the uniaxial stress-strain curve based on numerous results (Han, Yao, \& Zhao, 2005) is adopted for the constitutive relationship model of core concrete in compression and Gilbert's (Gilbert \& Warner, 1978) model in tensile behavior. A five-stage stress-strain curve for steel (Zhong, 2003) is adopted in simulation.

To verify the validity of the FE model, the experimental results are compared with the FE ones. Taking arch $\mathrm{A}$ as an example, the $F_{j}-d$ and $E_{j, \text { norm }}-F_{j}$ curves are shown in Figure 13. It can be seen that the curves of experimental and FE results are in good agreement and applicability. And the failure load detected by the $\mathrm{M}-\mathrm{K}$ method and the ultimate load are quite close to each other in the experimental and FE $E_{j, \text { norm }}-F_{j}$ curves. Hence, the FE model can effectively reflect the stressing state characteristics of CFST arches.

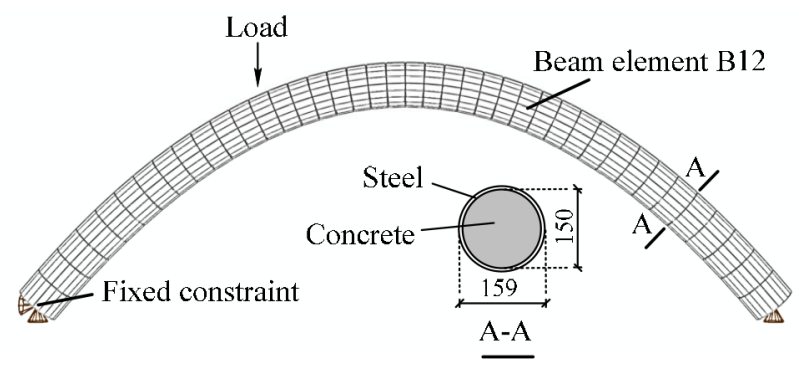

Figure 12. The FE model of the CFST arch
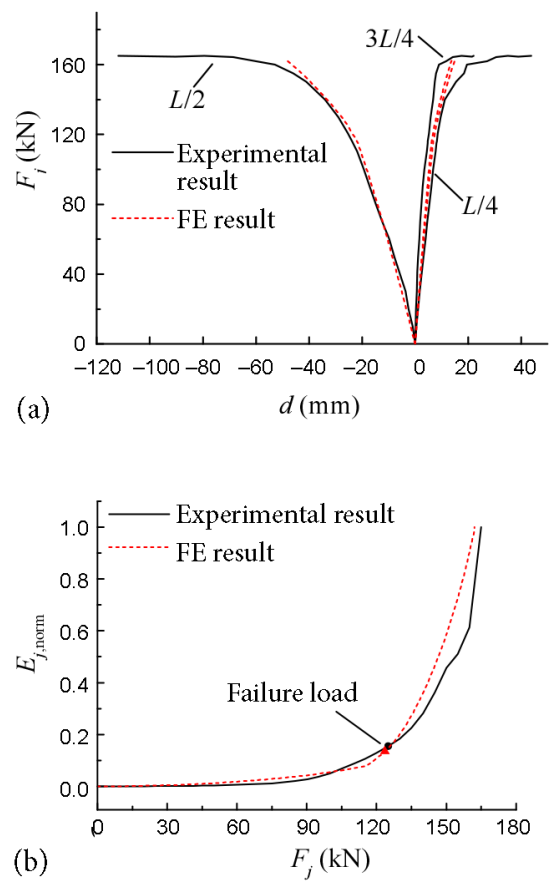

Figure 13. The comparison of the experimental and simulative results of arch A: a - the $F_{j}-d$ curve; b - the $E_{j, \text { norm }}{ }^{-} F_{j}$ curve

\subsection{The effects of parameters on failure loads of CFST arches}

The validated FE model is used to calculate the responses of the CFST arches under the conditions of different rise-span ratios $(f / L=0.2-0.4)$, slenderness ratio $(\lambda=60-160)$, steel ratio $\left(\alpha_{s}=0.06-0.14\right)$, strength of steel $\left(f_{y}=235 \mathrm{MPa}-400 \mathrm{MPa}\right)$ or concrete $\left(f_{c}=\mathrm{C} 30-\mathrm{C} 60\right)$; correspondingly, the failure loads or ultimate loads are obtained in more than 300 cases in total. Table 2 just lists the results of some typical cases, where $Q_{1}-Q_{3}$ or $U_{1}-U_{3}$ are the failure/ultimate loads of the CFST arches under loading case 1, 2 and 3, respectively. Obviously, the failure/ ultimate load of the CFST arch basically increases with the increase of the rise-span ratio $f / L$, the steel ratio $a_{s}$ and the yield strength of steel $f_{y}$ but the decrease of the slenderness ratio $\lambda$. Moreover, the failure load increases slightly with the increase of the strength grade of concrete $f_{c}$, indicating that $f_{c}$ has little influence on the failure load. This analysis provides a reference to the coming design and further investigation of CFST arches.

\section{Formula for predicting failure load and verification}

The failure/ultimate load of the CFST arch is dependent on not only loading conditions, but also configurational and material parameters (Campione \& Scibilia, 2002; N. Li, Lu, S. Li, \& Liang, 2015). Considering these factors and referring to the standards (GB50923-2013, 2013) for calculating the load-bearing capacity of the arch, a general expression for predicting the failure/ultimate loads of the CFST arches is proposed as 
Table 2. The parameters, failure loads and ultimate loads of the simulative CFST arches

\begin{tabular}{|c|c|c|c|c|c|c|c|c|c|c|c|}
\hline No. & $f / L$ & $l$ & $a_{s}$ & $f_{y}(\mathrm{MPa})$ & $f_{c}(\mathrm{MPa})$ & $Q_{1}(\mathrm{kN})$ & $Q_{2}(\mathrm{kN})$ & $Q_{3}(\mathrm{kN})$ & $U_{1}(\mathrm{kN})$ & $U_{2}(\mathrm{kN})$ & $U_{3}(\mathrm{kN})$ \\
\hline 1 & 0.25 & 100 & 0.10 & 345 & 40 & 100.51 & 70.56 & 170.75 & 144.04 & 97.02 & 217.15 \\
2 & 0.30 & 100 & 0.10 & 345 & 40 & 113.53 & 83.23 & 199.48 & 168.40 & 120.43 & 254.00 \\
3 & 0.35 & 100 & 0.10 & 345 & 40 & 130.87 & 90.53 & 233.78 & 199.88 & 135.47 & 300.05 \\
\hline 4 & 0.30 & 90 & 0.10 & 345 & 40 & 156.74 & 116.70 & 258.59 & 234.40 & 167.46 & 616.60 \\
5 & 0.30 & 110 & 0.10 & 345 & 40 & 84.87 & 62.01 & 157.49 & 125.28 & 89.76 & 332.48 \\
\hline 6 & 0.30 & 100 & 0.08 & 345 & 40 & 99.91 & 71.49 & 177.54 & 146.78 & 104.04 & 226.04 \\
7 & 0.30 & 100 & 0.12 & 345 & 40 & 125.98 & 93.70 & 226.76 & 183.90 & 131.44 & 273.91 \\
\hline 8 & 0.30 & 100 & 0.10 & 300 & 40 & 100.66 & 76.85 & 176.88 & 156.48 & 111.96 & 238.39 \\
9 & 0.30 & 100 & 0.10 & 400 & 40 & 128.92 & 90.95 & 225.58 & 182.61 & 130.55 & 272.07 \\
10 & 0.30 & 100 & 0.10 & 345 & 35 & 111.51 & 82.47 & 194.60 & 163.64 & 116.86 & 244.65 \\
11 & 0.30 & 100 & 0.10 & 345 & 45 & 115.50 & 85.41 & 203.49 & 173.14 & 123.04 & 263.03 \\
\hline
\end{tabular}

$$
F=\left(\frac{f}{L}\right)^{\alpha} \lambda^{\beta}\left[\pi\left(2 \frac{L}{\lambda}\right)^{2}\right]\left[\delta\left(1-\alpha_{s}\right) f_{c}+\mu \alpha_{s} f_{y}\right],
$$

where $F$ is the failure load $(Q)$ or the ultimate load $(U)$ (unit: $N$ ) $\alpha, \beta, \delta$ and $\mu$ are the fitted exponent or coefficient obtained by the simulative results, and these parameters are different under different circumstances, as shown in Table 3.

Table 3. The fitted parameters of Eqn (16)

\begin{tabular}{|c|c|c|c|c|c|}
\hline$F$ & Loading case & $\alpha$ & $\beta$ & $\mathrm{d}$ & $\mathrm{m}$ \\
\hline \multirow{4}{*}{$Q$} & 1 & 1.028 & -0.659 & 1.689 & 2.500 \\
& 2 & 0.691 & -1.052 & 11.150 & 20.036 \\
& 3 & 1.029 & -0.662 & 1.292 & 1.902 \\
\hline \multirow{4}{*}{$U$} & 1 & $46 / 195$ & 0.607 & -1.103 & 22.606 \\
& 2 & 0.712 & -1.091 & 10.498 & 18.800 \\
& 3 & 0.633 & -1.100 & 17.585 & 31.785 \\
\hline
\end{tabular}

The error (Er) between the load $F$ calculated by Eqn (16) and the simulative load $F_{\text {true }}$ is calculated by Eqn (17):

$$
E r=\frac{F-F_{\text {true }}}{F_{\text {true }}} \times 100 \% .
$$

Figure 14 gives out the range of errors between $F$ and $F_{\text {true }}$ under loading cases 1-3. The average errors are just within $0.02 \%-0.37 \%$. It could be stated for so small average errors that there should be a definite and unified relationship (Eqn (16)) between failure/ultimate loads of CFST arches. This provides a reference to the improvement of the existing design formulas of CFST arches. It should be stated once again that the reference is not from the empirical and statistical result in traditional structural analysis, instead of an essential and definite law which the CFST arches certainly follow according to the natural law from quantitative change to qualitative change of a system. Therefore, the theory, methods and results presented in this study could explore a way to reveal structural working behavior characteristics unseen in the existing structural analysis and then to update the existing design codes of structures on the basis of the physical law.
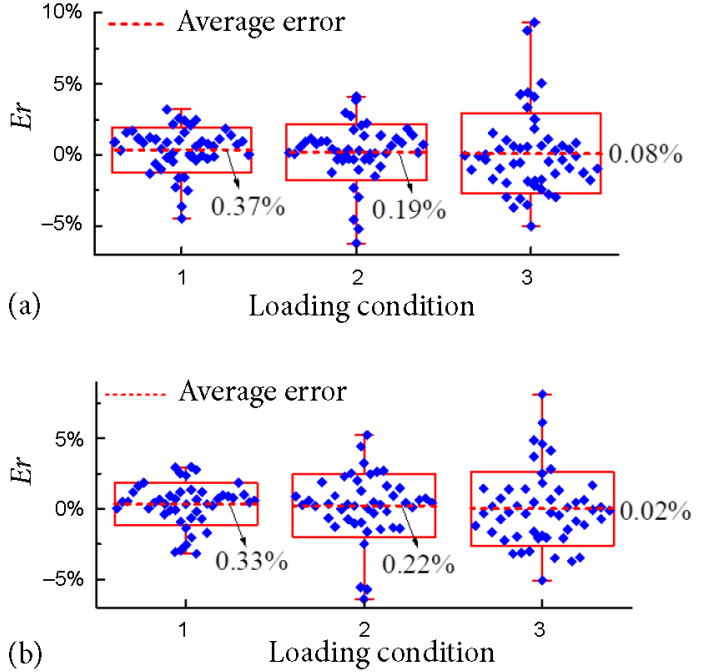

Figure 14. The range of the errors under three different loading cases for calculating failure and ultimate loads of the CFST arches: $\mathrm{a}$ - the calculating errors of failure loads; $\mathrm{b}$ - the calculating errors of ultimate loads

\section{Conclusions}

For the CFST arches, the normalized GSED values can effectively model structural stressing states and reflect their working behavior features. The $\mathrm{M}-\mathrm{K}$ criterion can reveal the qualitative leap characteristic of structural stressing state, complying with the natural law from quantitative change to qualitative change of a system. This characteristic reflects the essential and general failure property of the CFST arch, so that the definition of the existing failure load is updated according to the characteristic.

The NSF-based analysis and the FE simulation of the CFST arches verify the structural stressing state characteristics revealed from the corresponding experimental investigation. Besides, the axial and bending stressing state submodes can be formed to reflect their roles in structural stressing state and structural failure process.

The relation between the updated failure loads of the CFST arches can be formulated and simply verified by the experimental/FE data. The relation provides a reference to 
the accurate calculation of the CFST arches' failure loads on the basis of the physical law.

The achieved results explore a new way to deeply investigate structural working behavior characteristics based on experimental and numerical data, and provide an accurate method for predicting structural failure loads. Also, this way could provide a guidance to promote engineering design and practice.

\section{Acknowledgements}

This work was financially supported by the National Natural Science Foundation of China (Grant Nos. 51508132, 51508133 and 51608069). The authors would like to express their gratitude to Liu Changyong and Wu Xinrong for carrying out the excellent CFST arch bridge model experiments and giving the experimental data in details in their dissertation thesis. The authors would also like to thank members of the HIT 504 office for their selfless help and useful suggestions.

\section{Funding}

This work was supported by the $<$ National Natural Science Foundation of China \#1> under Grant [number 51508132]; < National Natural Science Foundation of China \#2> under Grant [number 51508133]; and < National Natural Science Foundation of China \#3> under Grant [number 51608069].

\section{Author contributions}

Zhou Guangchun, Huang Yanxia and Shi Jun conceived the study and were responsible for the design and development of the data analysis. Shi Jun and Yang Kangkang were responsible for data collection, analysis and interpretation. Zheng kaikai and Shen Jiyang helped perform the analysis with constructive discussions. Yang Kangkang wrote the first draft of the article.

\section{Disclosure statement}

All the authors have no conflict of interest.

\section{References}

Abaqus, Inc. (2009). Abaqus analysis user's manuals and example problems manuals (Version 6.9). Providence, Rhode Island.

Ayers, P. W. (2006). Information theory, the shape function, and the hirshfeld atom. Theoretical Chemistry Accounts, 115(5), 370-378. https://doi.org/10.1007/s00214-006-0121-5

Campione, G., \& Scibilia, N. (2002). Beam-column behavior of concrete filled steel tubes. Steel and Composite Structures, 2(4), 259-276. https://doi.org/10.12989/scs.2002.2.4.259

Cancelliere, I., Imbimbo, M., \& Sacco, E. (2010). Experimental tests and numerical modeling of reinforced masonry arches. Engineering Structures, 32(3), 776-792.

https://doi.org/10.1016/j.engstruct.2009.12.005
Chen, B. C. (2007, September 12-14). An overview of concrete and CFST arch bridges in China. In Proceedings of the $5^{\text {th }}$ International Conference on Arch Bridges. Madeira, Portugal.

Chen, B. C., \& Chen, Y. J. (2000). Experimental study on mechanic behaviors of concrete-filled steel tubular rib arch under in-plane loads. Engineering Mechanics, 17(2), 44-50. https://doi.org/10.3969/j.issn.1000-4750.2000.02.007

Chen, S. M., \& Zhang, H. F. (2012). Numerical analysis of the axially loaded concrete filled steel tube columns with debonding separation at the steel-concrete interface. Steel and Composite Structures, 13(3), 277-293. https://doi.org/10.12989/scs.2012.13.3.277

Dessouki, A. K., Yousef, A. H., \& Fawzy, M. M. (2014). Stiffener configurations of beam to concrete-filled tube column connections. Steel \& Composite Structures, 17(1), 83-103. https://doi.org/10.12989/scs.2014.17.1.083

GB50923-2013. (2013). Technical code for concrete-filled steel tube arch bridges (Chinese standard). Retrieved from http://www.bjkangdi.cn/upload/20170628145951.pdf

Geng, Y., Wang, Y., Ranzi, G., \& Wu, X. (2014). Time-dependent analysis of long-span, concrete-filled steel tubular arch bridges. Journal of Bridge Engineering, 19(4), 04013019. https://doi.org/10.1061/(ASCE)BE.1943-5592.0000549

Gilbert, R. L., \& Warner, R. F. (1978). Tension stiffening in reinforced concrete slabs. Journal of Structural Division, 104(12), 1885-1900.

Han, L. H. (2000). The influence of concrete compaction on the strength of concrete filled steel tubes. Advances in Structural Engineering, 3(2), 131-137. https://doi.org/10.1260/1369433001502076

Han, L. H. (2007). Concrete-filled steel tubular structures: Theories and applications ( $2^{\text {nd }}$ ed.). Beijing: Science Press (in Chinese).

Han, L. H., Yao, G. H., \& Zhao, X. L. (2005). Tests and calculations for hollow structural steel (HSS) stub columns filled with self-con-solidating concrete (SCC). Journal of Constructional Steel Research, 61(9), 1241-1269. https://doi.org/10.1016/j.jcsr.2005.01.004

Han, X., Zhu, B., Liu, G. M., Wang, J. P., \& Xiang, B. S. (2013). The analysis of double-nonlinearity stability of concrete filled steel-tube arch bridge. Advanced Materials Research, 724725, 1709-1713. https://doi.org/10.4028/www.scientific.net/ AMR.724-725.1709

Hirsch, R. M., Slack, J. R., \& Smith, R. A. (1982). Techniques of trend analysis for monthly water quality data. Water Resources Research, 18(1), 107-121. https://doi.org/10.1029/WR018i001p00107

Huang, Y. X., Zhang, Y., Zhang, M., \& Zhou, G. C. (2014). Method for predicting the failure load of masonry wall panels based on generalized strain-energy density. Journal of Engineering Mechanics, 140(8), 04014061. https://doi.org/10.1061/(ASCE)EM.1943-7889.0000771

Kendall, M. G. (1957). Rank correlation methods. Biometrika, 44(1/2), 298. https://doi.org/10.2307/2333282

Li, N., Lu, Y. Y., Li, S., \& Liang, H. J. (2015). Statistical-based evaluation of design codes for circular concrete-filled steel tube columns. Steel \& Composite Structures, 18(2), 519-546. https://doi.org/10.12989/scs.2015.18.2.519

Li, Z. L., \& Zhou, P. Y. (2011). Research on overall stability of concrete-filled steel tubular bowstring arch bridge. Advanced Materials Research, 243-249, 1988-1994. https://doi.org/10.4028/www.scientific.net/AMR.243249.1988 
Liu, C. Y., Wang, W. Y., Wu, X. R., \& Zhang, S. M. (2017). Inplane stability of fixed concrete-filled steel tubular parabolic arches under combined bending and compression. Journal of Bridge Engineering, 22(2), 04016116. https://doi.org/10.1061/ (ASCE)BE.1943-5592.0000993

Liu, Y., Wang, D., \& Zhu, Y. Z. (2011). Analysis of ultimate load-bearing capacity of long-span CFST arch bridges. Applied Mechanics \& Materials, 90-93(1), 1149-1156. https://doi. org/10.4028/www.scientific.net/AMM.90-93.1149

Luo, K., Pi, Y. L., Gao, W., Bradford, M. A., \& Hui, D. (2015). Investigation into long-term behaviour and stability of concrete-filled steel tubular arches. Journal of Constructional Steel Research, 104, 127-136. https://doi.org/10.1016/j.jcsr.2014.10.014

Ma, Y. S., Wang, Y. F., Su, L., \& Mei, S. Q. (2016). Influence of creep on dynamic behavior of concrete filled steel tube arch bridges. Steel \& Composite Structures, 21(1), 109-122. https://doi.org/10.12989/scs.2016.21.1.109

Mann, H. B. (1945). Nonparametric tests against trend. Econometrica, 13(3), 245-259. https://doi.org/10.2307/1907187

Padhi, G. S., Shenoi, R. A., Moyb, S. S. J., \& Mccarthya, M. A. (2001). Analytic integration of kernel shape function product integrals in the boundary element method. Computers \& Structures, 79(14), 1325-1333. https://doi.org/10.1016/S0045-7949(01)00020-7

Pi, Y. L., \& Trahair, N. S. (1999). In-plane buckling and design of steel arches. Journal of Structural Engineering, 125(11), 1291-1298. https://doi.org/10.1061/(ASCE)07339445(1999)125:11(1291)

Pi, Y. L., Liu, C. Y., Bradford, M. A., \& Zhang, S. M. (2012). Inplane strength of concrete-filled steel tubular circular arches. Journal of Constructional Steel Research, 69(1), 77-94. https://doi.org/10.1016/j.jcsr.2011.08.008
Rovero, L., Focacci, F., \& Stipo, G. (2013). Structural behavior of arch models strengthened using fiber-reinforced polymer strips of different lengths. Journal of Composites for Construction, 17(2), 249-258. https://doi.org/10.1061/(ASCE) CC.1943-5614.0000325

Shi, J., Li, P. C., Chen, W. Z., Zheng, K. K., \& Zhou, G. C. (2018). Structural state of stress analysis of concrete-filled stainless steel tubular short columns. Journal of Stahlbau, 87(6), 600610. https://doi.org/10.1002/stab.201810610

Wang, X. C. (2003). Finite element method. Beijing: Tsinghua University Press Publishers (in Chinese).

Wu, X. R., Liu, C. Y., Wang, W., \& Wang, Y. Y. (2015). In-plane strength and design of fixed concrete-filled steel tubular parabolic arches. Journal of Bridge Engineering, 20(12), 04015016. https://doi.org/10.1061/(ASCE)BE.1943-5592.0000766

Xiao, C. Z., Cai, S. H., Chen, T., \& Xu, C. L. (2012). Experimental study on shear capacity of circular concrete filled steel tubes. Steel \& Composite Structures, 13(5), 437-449. https://doi.org/10.12989/scs.2012.13.5.437

Yin, X., \& Lu, X. (2010). Study on push-out test and bond stressslip relationship of circular concrete filled steel tube. Steel \& Composite Structures, 10(4), 317-329. https://doi.org/10.12989/scs.2010.10.4.317

Yoshimura, M., Wu, Q. X., Takahashi, K., Nakamura, S., \& Furukawa, K. (2006). Vibration analysis of the second Saikai Bridge: A concrete filled tubular (CFT) arch bridge. Journal of Sound and Vibration, 290(1/2), 388-409. https://doi.org/10.1016/j.jsv.2005.04.004

Zhong, S. T. (2003). The concrete-filled steel tubular structures. Beijing: Tsinghua University Press Publishers (in Chinese). 